\title{
Recent climate and ice-sheet changes in West Antarctica compared with the past 2,000 years
}

\author{
Eric J. Steig ${ }^{1 \star}$, Qinghua Ding ${ }^{1}$, James W. C. White ${ }^{2}$, Marcel Küttel ${ }^{1}$, Summer B. Rupper ${ }^{3}$, \\ Thomas A. Neumann ${ }^{4}$, Peter D. Neff ${ }^{1 \dagger}$, Ailie J. E. Gallant ${ }^{1 \dagger}$, Paul A. Mayewski ${ }^{5}$, Kendrick C. Taylor ${ }^{6}$, \\ Georg Hoffmann ${ }^{7,8}$, Daniel A. Dixon ${ }^{5}$, Spruce W. Schoenemann ${ }^{1}$, Bradley R. Markle ${ }^{1}$, Tyler J. Fudge ${ }^{1}$, \\ David P. Schneider ${ }^{9}$, Andrew J. Schauer ${ }^{1}$, Rebecca P. Teel ${ }^{1}$, Bruce H. Vaughn ${ }^{2}$, Landon Burgener ${ }^{3}$, \\ Jessica Williams ${ }^{3}$ and Elena Korotkikh ${ }^{5}$
}

Changes in atmospheric circulation over the past five decades have enhanced the wind-driven inflow of warm ocean water onto the Antarctic continental shelf, where it melts ice shelves from below ${ }^{1-3}$. Atmospheric circulation changes have also caused rapid warming ${ }^{4}$ over the West Antarctic Ice Sheet, and contributed to declining sea-ice cover in the adjacent Amundsen-Bellingshausen seas ${ }^{5}$. It is unknown whether these changes are part of a longer-term trend. Here, we use waterisotope $\left(\delta^{18} 0\right)$ data from an array of ice-core records to place recent West Antarctic climate changes in the context of the past two millennia. We find that the $\delta^{18} \mathrm{O}$ of West Antarctic precipitation has increased significantly in the past $\mathbf{5 0}$ years, in parallel with the trend in temperature, and was probably more elevated during the 1990 s than at any other time during the past 200 years. However, $\delta^{18} 0$ anomalies comparable to those of recent decades occur about $1 \%$ of the time over the past 2,000 years. General circulation model simulations suggest that recent trends in $\delta^{18} O$ and climate in West Antarctica cannot be distinguished from decadal variability that originates in the tropics. We conclude that the uncertain trajectory of tropical climate variability represents a significant source of uncertainty in projections of West Antarctic climate and ice-sheet change.

The West Antarctic Ice Sheet (WAIS), which is grounded largely below sea level, is potentially unstable. Mass loss from the WAIS is contributing to present sea-level rise, owing to the widespread thinning of ice shelves and the acceleration of the large outlet glaciers that drain the ice sheet into the ocean ${ }^{1}$. Contemporaneous with the loss of mass from the WAIS, air temperatures over the WAIS have increased significantly in the past 50 years ${ }^{4,6,7}$.

Climate and ice-sheet changes in West Antarctica are closely linked with one another by changes in regional atmospheric circulation $^{8}$. Observations beneath the floating ice shelf of Pine Island Glacier, a major drainage system for the flow of the WAIS into the Amundsen Sea, show that the primary cause of ice-shelf thinning is the presence of warm Circumpolar Deep Water on

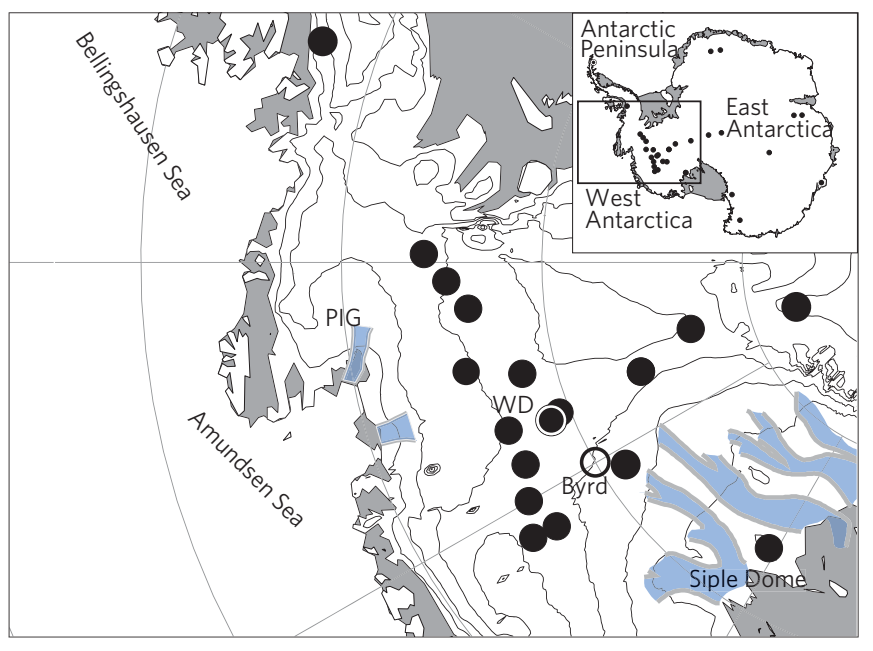

Figure 1 | Map of West Antarctica. Ice-core locations are shown by filled circles. Blue shading shows the main Siple Coast and Amundsen Sea ice streams. Ice shelves are shaded grey. The inset map shows the locations of well-dated, annually resolved ice cores for which there are $\delta^{18} \mathrm{O}$ data available to at least 1994. WD, WAIS Divide ice core (white-edged circle). PIG, Pine Island Glacier. The location of the Byrd weather station is shown by an open circle.

the Antarctic continental shelf ${ }^{3}$. Circumpolar Deep Water inflow onto the continental shelf probably increased between the 1980s and 1990s because of increased wind stress at the shelf edge $e^{2,8}$. The patterns of sea-level pressure and geopotential height anomalies associated with increased westerly wind stress $^{8}$ also favour reduced sea-ice extent ${ }^{9}$ and the advection of warm air onto the continent $t^{4,10}$.

It is unknown whether the climate and glaciological changes that have occurred in West Antarctica in recent decades are part of a longer-term trend associated with anthropogenic climate forcing. This question cannot be evaluated with direct observations.

\footnotetext{
${ }^{1}$ Quaternary Research Center and Department of Earth and Space Sciences, University of Washington, Seattle, Washington 98195, USA, ${ }^{2}$ Institute of Arctic and Alpine Research, University of Colorado, Boulder, Colorado 80303, USA, ${ }^{3}$ Department of Geological Sciences, Brigham Young University, Provo, Utah 84602, USA, ${ }^{4}$ NASA Goddard Space Flight Center, Code 615, Greenbelt, Maryland 20770, USA, ${ }^{5}$ Climate Change Institute and School of Earth and Climate Sciences, University of Maine, Orono, Maine 04469, USA, ${ }^{6}$ Desert Research Institute, Reno, Nevada 89512, USA, ${ }^{7}$ Laboratoire des Sciences du Climat et de I'Environnement, Centre d'Etudes de Saclay, Gif-sur-Yvette 91191, France, ${ }^{8}$ Institute for Marine and Atmospheric Research, Utrecht University, Utrecht 3508 TC, Netherlands, ${ }^{9}$ National Center for Atmospheric Research, Boulder, Colorado 80305, USA. ${ }^{\dagger}$ Present addresses: Antarctic Research Centre, Victoria University of Wellington, Wellington 6140, New Zealand (P.D.N.); School of Geography and Environmental Science, Monash University, Clayton, Victoria 3800, Australia (A.J.E.G.). *e-mail: steig@uw.edu.
} 


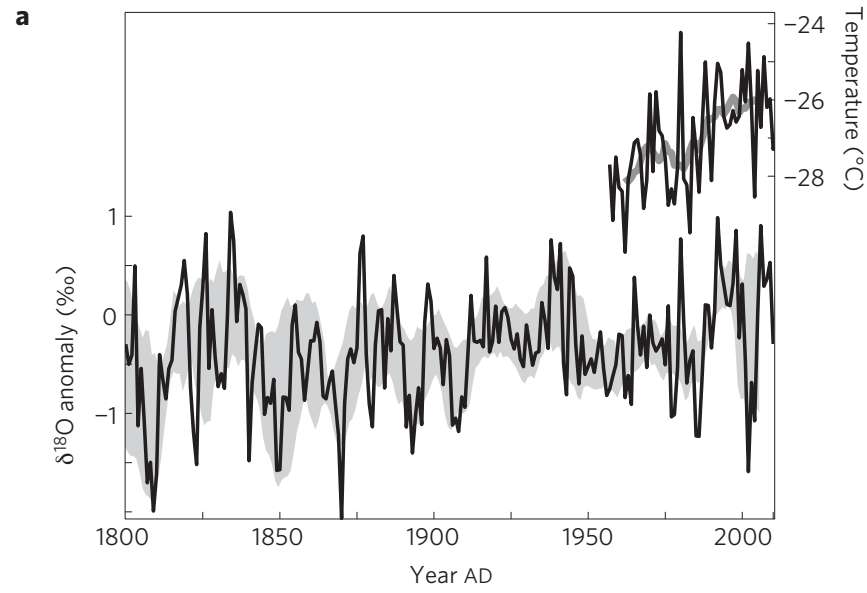

b

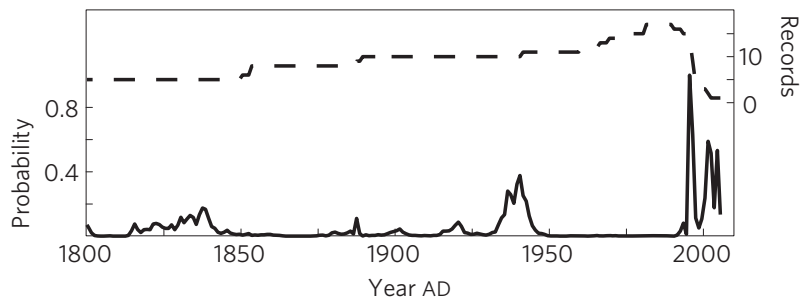

Figure 2 | West Antarctic temperature and $\boldsymbol{\delta}^{18} \mathbf{O}$. a, Temperature ${ }^{7}$ at Byrd Station ( $80^{\circ} \mathrm{S}, 120^{\circ} \mathrm{W}$ ) (upper) and composite of annual mean $\delta^{18} \mathrm{O}$ anomalies from ice cores in West Antarctica (lower). The two time series are correlated at $r=0.48, p=0.01$. Grey shading shows the running decadal mean of temperature and the standard error of the running decadal mean of $\delta^{18} \mathrm{O}$. b, Probability from a one-tailed $t$-test that decadal mean West Antarctic $\delta^{18} \mathrm{O}$ centred on any given year is as elevated as the decade of the 1990s (1991-2000). The dashed line shows the number of records contributing to each decadal mean.

West Antarctic temperature and pressure observations begin only in 1957, and reliable satellite observations of Antarctic sea ice date to 1979. Comprehensive observations of glacier dynamics in the most rapidly changing areas were initiated in the 1990s. Borehole temperature data from the WAIS, although confirming the recent rapid rise in temperature, do not resolve decadal-scale variability in the past ${ }^{6}$.

Here, we use records of the oxygen isotopic composition of precipitation $\left(\delta^{18} \mathrm{O}\right.$, see Methods) from ice cores to assess the significance of recent West Antarctic climate trends, and to place the observed glaciological changes in a longer-term context. Unlike temperature or other conventional climate variables, $\delta^{18} \mathrm{O}$ is relatively well sampled in West Antarctica and thus provides the best available data for this purpose. We use a network of ice cores (Fig. 1) that includes sixteen new and updated multi-decade to centurylength records from across the WAIS, and a new 2000-year-long record from the central ice divide (WAIS Divide).

The use of $\delta^{18} \mathrm{O}$ in precipitation as a proxy for temperature is well known, and supported by our data. However, we do not use $\delta^{18} \mathrm{O}$ as a proxy for temperature. Rather, we observe that $\delta^{18} \mathrm{O}$ in West Antarctica covaries with atmospheric circulation in a manner similar to temperature. Positive anomalies in both nearsurface temperature and $\delta^{18} \mathrm{O}$ of precipitation in West Antarctica arise when anomalous meridional flow in the troposphere advects warmer air from lower latitudes, reducing the net distillation of water vapour that otherwise progressively lowers $\delta^{18} \mathrm{O}$ values in precipitation ${ }^{11}$. The $\delta^{18} \mathrm{O}$ of precipitation in West Antarctica is also increased by reduced sea-ice cover, owing both to an increase in the fraction of locally derived moisture, and an increase in boundarylayer turbulence that produces more effective penetration of local

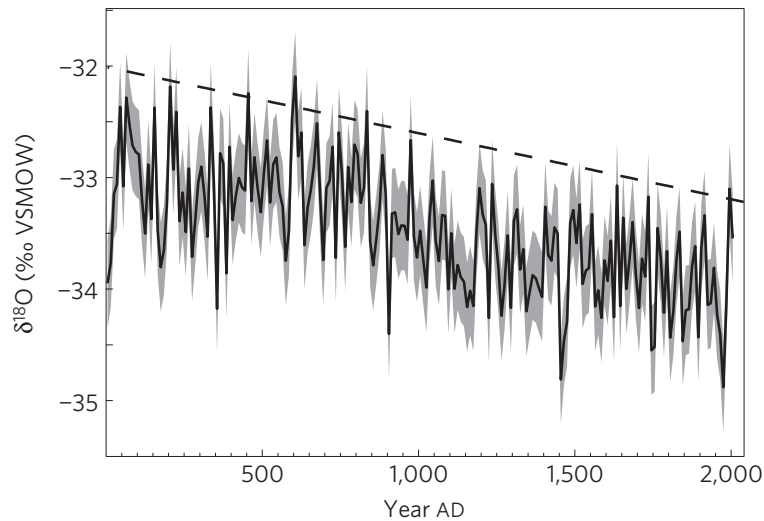

Figure 3 | Decade-average $\delta^{18} \mathrm{O}$ from the WAIS Divide ice core for the past 2,000 years. Grey shading shows 2 s.d. about the decadal mean, based on the upper 100 years of the multi-core $\delta^{18} \mathrm{O}$ composite, providing an estimate of the $95 \%$ confidence range. The dashed line shows the 97.5 percentile value relative to the average linear trend.

maritime air masses onto the continent ${ }^{12}$. West Antarctic $\delta^{18} \mathrm{O}$ thus reflects the same circulation anomalies that have contributed to the trends in temperature, sea ice and the glaciologically significant ocean circulation changes of the past few decades.

Figure 2 shows $\delta^{18} \mathrm{O}$ averaged over the West Antarctic ice-core records for the past 200 years. A prominent feature is the elevated $\delta^{18} \mathrm{O}$ of the 1990s and significant upward trend since the 1950s, consistent with the surface temperature trend ${ }^{4,6,7}$. In nearly all of the individual ice-core records, the highest $\delta^{18} \mathrm{O}$ values occur after 1985, and the mean decadal maximum occurs during the 1990s (1991-2000). The limited available data indicate lower values during the 2000s. The mean upward trend in $\delta^{18} \mathrm{O}$ over the past 50 years therefore primarily reflects the anomalous values of the 1990s.

Before the 1990s, there are two other prominent decadal-scale anomalies in West Antarctic $\delta^{18} \mathrm{O}$ in the past two centuries: the 1830 s and the 1940s (1936-1945). We use the population statistics from the ice-core records to assess the level of confidence at which the $\delta^{18} \mathrm{O}$ values of these decades, averaged over West Antarctica, are distinguishable from the 1990s maximum (Methods). The results (Fig. 2) show that decadal-average $\delta^{18} \mathrm{O}$ since 1990 is probably more elevated than that of the 1830s and 1940s, but only at low confidence ( $p \sim 0.2$ and $p \sim 0.3$, respectively). It is extremely likely $(p<0.05)$ that the mean $\delta^{18} \mathrm{O}$ of the decade 1991-2000 was more elevated than during any decade in the previous 40 years, consistent with the evidence for widespread warming and large-scale changes in atmospheric circulation ${ }^{4,10}$.

Analysis of the long record at WAIS Divide shows that $\delta^{18} \mathrm{O}$ in West Antarctica is anomalous not only with respect to the past two centuries, but also with respect to the past two millennia. WAIS Divide is well situated to be representative of West Antarctica as a whole: the WAIS Divide $\delta^{18} \mathrm{O}$ record is equally well correlated with $\delta^{18} \mathrm{O}$ records from cores east and west of the ice divide ${ }^{11}$. Decadal-average $\delta^{18} \mathrm{O}$ values comparable to the 1990s in the WAIS Divide record are reached on only four occasions in the past 1,000 years (Fig. 3). Before 1,000 years ago, modern decadal-average $\delta^{18} \mathrm{O}$ values are reached more frequently, but these are superimposed on a declining trend attributable to the influence of Milankovitch orbital forcing and ice flow ${ }^{13}$. Assuming that the decadal variability is independent of orbital forcing, we calculate $\delta^{18} \mathrm{O}$ anomalies relative to the long-term trend (dashed line in Fig. 3). Anomalies in $\delta^{18} \mathrm{O}$ similar to those of the 1990s occur just twice in the past 2,000 years; assuming sampling error estimated from the multiple shorter records, comparably elevated $\delta^{18} \mathrm{O}$ values were reached about $1 \%$ of the time. Analysis of trends yields a similar result: trends in $\delta^{18} \mathrm{O}$ as large as the most recent 50 -year trend in the WAIS Divide 


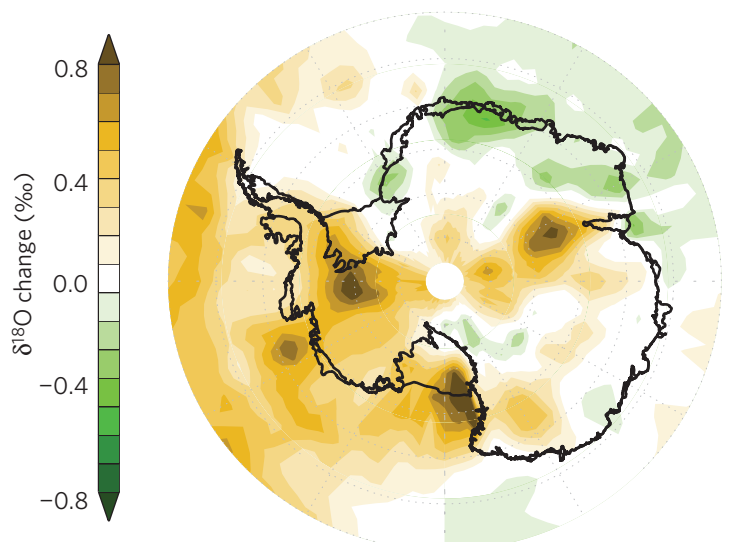

b

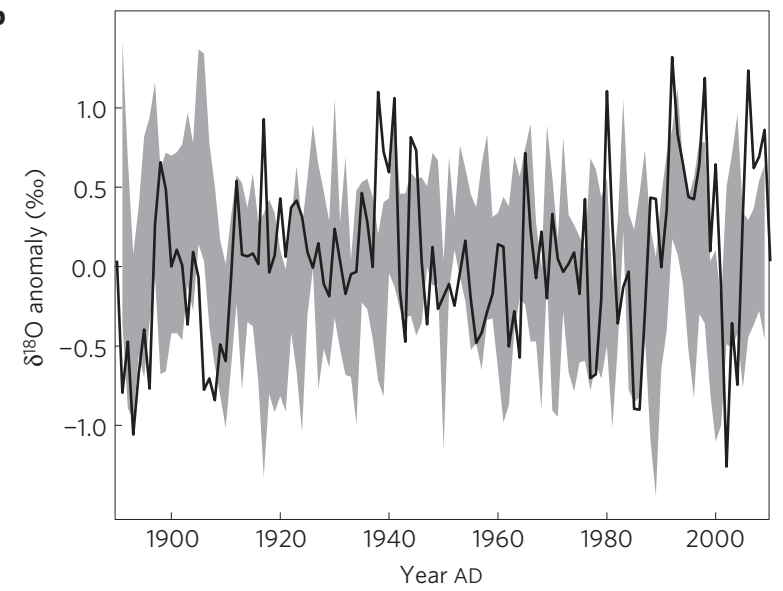

c

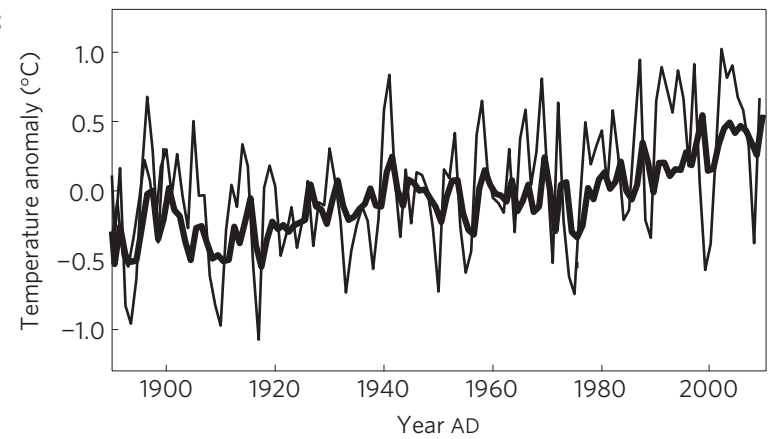

Figure 4 | Modelled versus observed West Antarctic $\delta^{18} \mathrm{O}$ and tropical SSTs. a, Difference in mean simulated decadal-mean $\delta^{18} \mathrm{O}$ in Antarctic precipitation between 1991 and 2000 and the three preceding decades. b. Model range ( 2 s.d., grey shading) of simulated annual mean $\delta^{18} \mathrm{O}$ in precipitation averaged over West Antarctica compared with observed $\delta^{18} \mathrm{O}$ anomalies (black line). In both $\mathbf{a}$ and $\mathbf{b}$, the model simulations are from 10-member ensembles of ECHAM4.6 simulations forced by global tropical SST with a slab ocean in the extratropics. c, SST anomalies ${ }^{26}$ averaged over the central tropical Pacific Niño4 region (thin solid line) and over the entire tropics (thick line), 1880-2009.

record is reached $\sim 2 \%$ of the time in the past 2,000 years. Hence, the anomalous $\delta^{18} \mathrm{O}$ values of recent decades in West Antarctica do not seem to be unprecedented, but are near the upper limit of the range of natural variability. A similar conclusion has been reached for the northern Antarctic Peninsula, based on data from an ice core there ${ }^{14}$.

Recent climate trends in West Antarctica have been shown to result from anomalous convection over the tropical Pacific, propagated to the high latitudes by atmospheric Rossby waves ${ }^{9,10,15}$. Significant changes have also occurred in the large-scale circumpolar westerlies, expressed as an increase in the Southern Annular Mode (SAM) index, in austral summer ${ }^{16}$. Changes in the SAM may be reflected in dust and aerosol increases recorded in West Antarctic ice cores ${ }^{17}$. However, the largest trends in both temperature and in ice-core $\delta^{18} \mathrm{O}$ in West Antarctica have occurred in the nonsummer seasons, during which the influence of tropical forcing has dominated ${ }^{15}$. Comparisons of West Antarctic $\delta^{18} \mathrm{O}$ records with tropical sea surface temperature (SST) and rainfall records suggest an important role for the tropical Pacific in influencing West Antarctic decadal $\delta^{18} \mathrm{O}$ variability throughout the past 200 years ${ }^{18,19}$. Indeed, the statistics of climate variability in West Antarctic inferred from $\delta^{18} \mathrm{O}$ are similar to those for tropical Pacific climate. Although the 1990s were the warmest decade of the past century in the tropics, they are distinct from other decades only at moderate confidence ${ }^{20}$ and proxy SST data indicate that conditions similar to those of the 1990s in the tropical Pacific occur with a frequency of about twice per century over the past 350 years ${ }^{21}$.

The statistics of the ice-core $\delta^{18} \mathrm{O}$ records suggest that decadal variability in the tropical Pacific is sufficient to account both for the strong recent trends, and for the magnitude of decadal variability in West Antarctic climate over the past century. This is supported by simulations with a general circulation model (GCM). We used the ECHAM4.6 GCM (ref. 22), which has been shown previously to reproduce the magnitude and spatial pattern of observed atmospheric circulation and temperature change in West Antarctica in response to tropical SST boundary conditions ${ }^{10}$. When run with its water-isotope module ${ }^{23}$, ECHAM4.6 reproduces the characteristic spatial covariance relationships between $\delta^{18} \mathrm{O}$ in West Antarctic precipitation and geopotential height anomalies and SST seen in observations (Supplementary Information). When forced either by global observed SSTs or tropics-only SSTs, ECHAM4.6 captures the magnitude and spatial expression of the prominent 1990s decadal $\delta^{18} \mathrm{O}$ anomaly (Fig. 4). As in the observations, the simulated $\delta^{18} \mathrm{O}$ of the 1990s is significantly elevated compared with the past several decades, but is only marginally distinct from other decadal maxima over the past century. Furthermore, whereas there is a significant positive trend in the tropical SST boundary conditions in the past century, there is no significant trend in the resulting $\delta^{18} \mathrm{O}$ simulated over West Antarctica, consistent with the observations. This occurs because it is the pattern of warming in the tropics, rather than the mean temperature, that produces the Rossby-wave response ${ }^{10,24}$. The correlation between the forcing (tropical SST) and simulated $\delta^{18} \mathrm{O}$ time series is only marginally significant $(r=0.22, p=0.07)$, whereas the correlation between the central tropical Pacific SSTs and simulated $\delta^{18} \mathrm{O}$ is highly significant $(r=0.58, p<0.001)$.

Much attention has been given to the role of anthropogenic radiative forcing on Antarctic climate through the influence of both increasing greenhouse gases and stratospheric ozone decline on the SAM (ref. 16). Our results suggest that in West Antarctica the influence of natural decadal variability originating in the tropical Pacific has masked any anthropogenically forced response. A caveat is that there is a small but robust long-term trend in the pattern of tropical SSTs that may be interpreted as a response to radiative forcing ${ }^{25,26}$. However, most analyses suggest that observed changes in the key central Pacific and El Niño/Southern Oscillation regions that influence West Antarctic climate cannot be distinguished from stochastically forced variability ${ }^{20,26}$.

Our results have implications for the response of the West Antarctic Ice Sheet to anthropogenic forcing. How tropical Pacific climate will change in the future is uncertain, with some GCMs projecting a more El Niño-like state and others suggesting a tendency towards greater La Niña-like conditions ${ }^{27}$. These different possibilities have potentially quite different impacts on the regional circulation affecting West Antarctica, suggesting that tropical climate represents a significant source of uncertainty in West 
Antarctic climate, and in the contribution of the WAIS to sea level, over the next century. Moreover, some GCMs overestimate the magnitude of variability associated with the SAM (ref. 28)-the dominant response to radiative forcing in most models-and are therefore likely to underestimate the importance of variability associated with changes in the tropical Pacific. Indeed, largeensemble modelling studies show that internal variability associated with the tropics is a significant source of uncertainty in climatechange projections at high latitudes, especially for the atmospheric circulation $^{29}$. Projections of the contribution of the WAIS to future sea-level rise that are based on present rates of ice-sheet mass loss ${ }^{30}$ should be treated with caution.

\section{Methods}

Ice-core data presented in this manuscript include both previously published and new analyses of ice and firn cores, primarily from the United States' ITASE (International Trans-Antarctic Expedition). The development of depth-age scales for these cores was conducted using multi-parameter high-resolution chemistry. Water stable-isotope concentrations were measured by mass spectrometry and laser spectroscopy at the University of Washington, and are reported as $\delta^{18} \mathrm{O}$ deviations in per mil (\%o) from Vienna Standard Mean Ocean Water (VSMOW), normalized to VSMOW and SLAP (Standard Light Antarctic Precipitation), where $\delta^{18} \mathrm{O}=\mathrm{R} / \mathrm{R}_{\text {VSMOW }}-1, R$ is the abundance ratio of ${ }^{18} \mathrm{O} /{ }^{16} \mathrm{O}$ in water, $\delta^{18} \mathrm{O}_{\text {VSMOW }}=0.0 \%$ and $\delta^{18} \mathrm{O}_{\text {SLAP }}=-55.5 \%$. The ice-core $\delta^{18} \mathrm{O}$ composite record were produced by normalizing the mean over the data overlap period common to all cores. The spatial distribution of decadal-mean $\delta^{18} \mathrm{O}$ data from West Antarctic cores is indistinguishable from a normal distribution $(p<0.05)$ based on a Lilliefor goodness-of-fit test. We use a one-tailed Student's $t$-test of the null hypothesis that a given decade mean comes from the same population as the 1990s (1991-2000) mean. Use of the non-parameteric Wilcoxon rank-sum test yields indistinguishable results. The significance level $p$ of reported correlations accounts for the degrees of freedom reduced by the quotient $\left(1-r_{1} r_{2}\right) /\left(1+r_{1} r_{2}\right)$, where $r_{i}$ is the lag- 1 autocorrelation of time series $i$. The general circulation modelling results are from experiments with the ECHAM4.6 atmospheric GCM, at a horizontal resolution of T42 $\left(\sim 2.8^{\circ}\right.$ latitude $\times 2.8^{\circ}$ longitude) with 19 vertical levels, using observed SST (ref. 26) as a boundary condition. In experiments using only tropical SSTs as the boundary condition, the atmospheric GCM is coupled to a slab ocean in the extratropics.

Data. http://nsidc.org/data/nsidc-0536.html.

Received 11 July 2012; accepted 26 February 2013; published online 14 April 2013

\section{References}

1. Rignot, E. et al. Recent Antarctic ice mass loss from radar interferometry and regional climate modelling. Nature Geosci. 1, 106-110 (2008).

2. Thoma, M., Jenkins, A. \& Holland, D. Modelling circumpolar deep water intrusions on the Amundsen Sea continental shelf, Antarctica. Geophys. Res. Lett. 35, L18602 (2008).

3. Jenkins, A. et al. Observations beneath Pine Island Glacier in West Antarctica and implications for its retreat. Nature Geosci. 3, 468-472 (2010).

4. Steig, E. J. et al. Warming of the Antarctic ice-sheet surface since the 1957 International Geophysical Year. Nature 457, 459-462 (2009).

5. Comiso, J. C. \& Nishio, F. Trends in the sea ice cover using enhanced and compatible AMSR-E, SSM/I, and SMMR data. J. Geophys. Res. 113, C02S07 (2008).

6. Orsi, A. J., Cornuelle, B. D. \& Severinghaus, J. P. Little Ice Age cold interval in West Antarctica: Evidence from borehole temperature at the West Antarctic Ice Sheet (WAIS) Divide. Geophys. Res. Lett. 39, L09710 (2012).

7. Bromwich, D. H. et al. Central West Antarctica among the most rapidly warming regions on Earth. Nature Geosci. 6, 139-145 (2013).

8. Steig, E. J., Ding, Q., Battisti, D. S. \& Jenkins, A. Tropical forcing of Circumpolar Deep Water Inflow and outlet glacier thinning in the Amundsen Sea Embayment, West Antarctica. Annal. Glaciol. 53, 19-28 (2012).

9. Schneider, D. P., Deser, C. \& Okumura, Y. An assessment and interpretation of the observed warming of West Antarctica in the austral spring. Clim. Dyn. 38, 323-347 (2011).

10. Ding, Q., Steig, E. J., Battisti, D. S. \& Küttel, M. Winter warming in West Antarctica caused by central tropical Pacific warming. Nature Geosci. 4, 398-403 (2011).

11. Küttel, M., Steig, E. J., Ding, Q., Battisti, D. S. \& Monaghan, A. J. Seasonal climate information preserved in West Antarctic ice core water isotopes: Relationships to temperature, large-scale circulation, and sea ice. Clim. Dyn. 39, 1841-1857 (2012).
12. Noone, D. \& Simmonds, I. Sea ice control of water isotope transport to Antarctica and implications for ice core interpretation. J. Geophys. Res. 109, D07105 (2004).

13. Neumann, T. A. et al. Holocene accumulation and ice sheet dynamics in central West Antarctica. J. Geophys. Res. 113, F02018 (2008).

14. Mulvaney, R. et al. Recent Antarctic Peninsula warming relative to Holocene climate and ice shelf history. Nature 489, 141-144 (2012).

15. Ding, Q., Steig, E. J., Battisti, D. S. \& Wallace, J. M. Influence of the tropics on the Southern Annular Mode. J. Clim. 25, 6330-6348 (2012).

16. Thompson, D. W. J. et al. Signatures of the Antarctic ozone hole in Southern Hemisphere surface climate change. Nature Geosci. 4, 741-749 (2011).

17. Dixon, D. A. et al. An ice-core proxy for northerly air mass incursions into West Antarctica. Int. J. Climatol. 32, 1455-1465 (2012).

18. Schneider, D. P. \& Steig, E. J. Ice cores record significant 1940s Antarctic warmth related to tropical climate variability. Proc. Natl Acad. Sci. USA 105, 12154-12158 (2008).

19. Okumura, Y., Schneider, D. P., Deser, C. \& Wilson, R. Decadal-interdecadal climate variability over Antarctica and linkages to the tropics: Analysis of ice core, instrumental, and tropical proxy data. J. Clim. 25, 7421-7441 (2012).

20. Latif, M., Kleeman, R. \& Eckert, C. Greenhouse warming, decadal variability, or El Niño? An attempt to understand the anomalous 1990s. J. Clim. 10, 2221-2239 (1997).

21. McGregor, S., Timmermann, A. \& Timm, O. A unified proxy for ENSO and PDO variability since 1650 . Clim. Past 6, 1-17 (2010).

22. Roeckner, E. et al. The Atmospheric General Circulation Model ECHAM-4: Model Description and Simulation of Present-Day Climate (Max Planck Institut für Meteorologie Report 218, 90, 1996).

23. Hoffmann, G., Werner, M. \& Heimann, M. Water isotope module of the ECHAM atmospheric general circulation model: A study on timescales from days to several years. J. Geophys. Res. 103, 16871-16896 (1998).

24. Vance, T. et al. A millennial proxy record of ENSO and eastern Australian rainfall from the Law Dome ice core, East Antarctica. J. Clim. 26, 710-725 (2013).

25. Dinezio, P. N. et al. Climate response of the equatorial Pacific to global warming. J. Clim. 22, 4873-4892 (2009).

26. Solomon, A. \& Newman, M. Reconciling disparate twentieth-century Indo-Pacific ocean temperature trends in the instrumental record. Nature Clim. Change 2, 691-699 (2012).

27. Collins, M. et al. The impact of global warming on the tropical Pacific Ocean and El Niño. Nature Geosci. 3, 391-397 (2010).

28. Miller, R. L., Schmidt, G. A. \& Shindell, D. T. Forced annular variations in the 20th century Intergovernmental Panel on Climate Change Fourth Assessment Report models. J. Geophys. Res. 111, D18101 (2006).

29. Deser, C., Phillips, A. S., Bourdette, V. \& Teng, H. Uncertainty in climate change projections: The role of internal variability. Clim. Dyn. 38, 527-546 (2012).

30. Rignot, E., Velicogna, I., van den Broeke, M. R., Monaghan, A. \& Lenaerts, J. Acceleration of the contribution of the Greenland and Antarctic ice sheets to sea level rise. Geophys. Res. Lett. 38, L05503 (2011).

\section{Acknowledgements}

This work was supported by the National Science Foundation Office of Polar Programs (grant numbers 0537930, 0837988, 0963924 and 1043092 to E.J.S.; 05379853 and 1043167 to J.W.C.W.; 0944730 to S.B.R.; $0230396,0440817,0944348$ and 0944266 to K.C.T.; 0096305, 9316564, 0096299, 0424589, 0439589, 063740, 063650 and 0837883 to P.A.M.; 0838871 to D.P.S.). NCAR is sponsored by the National Science Foundation. We thank A. Orsi, J. Bautista and J. Flaherty.

\section{Author contributions}

E.J.S., J.W.C.W., S.B.R., P.D.N., B.R.M., B.H.V., D.P.S., S.W.S., T.A.N., P.A.M., K.C.T., T.J.F., D.A.D. and E.K. conducted fieldwork and sample collection. P.D.N., A.J.S., R.P.T., B.H.V., E.K., E.J.S., D.P.S., J.W.C.W., S.B.R., L.B. and J.W. obtained the ice-core water-isotope data. G.H. provided code and assistance with the modelling. E.J.S. and Q.D. compiled the data, conducted the model experiments and calculations and wrote the paper. All authors contributed to the final manuscript text.

\section{Additional information}

Supplementary information is available in the online version of the paper. Reprints and permissions information is available online at www.nature.com/reprints. Correspondence and requests for materials should be addressed to E.J.S.

\section{Competing financial interests}

The authors declare no competing financial interests. 